\title{
Optimization of Gasoline Engine Flywheel using Alternate Materials for Improving Performance Characteristics
}

\author{
Shubham Gupta*, Karan Kothari, Jay P. Mishra and B. Ashok \\ School of Mechanical and Building Sciences (SMBS), VIT-University, Vellore - 632014, Tamil Nadu, India; \\ shubhamgupta457@gmail.com, karan.kothari2013@gmail.com,_jaypmishra@ymail.com, ashok.b@vit.ac.in
}

\begin{abstract}
Background/Objectives: The present investigation guides through the design, analysis and material selection process of Subaru EJ25D gasoline engine flywheel to reduce the weight of the flywheel without compromising its performance. Methods/Statistical Analysis: The flywheel was modeled using 3D modeling software Solid works. The validation of the strength of the flywheel was done by calculating and applying the forces on the flywheel using ANSYS software. The Finite Element Analysis (FEA) was conducted by considering the centrifugal forces acting on the flywheel. Structural analysis of the flywheel was done to validate the use of the alternate materials for constructing the flywheel. A comparative analysis of the stresses, total deformation and safety factor of the flywheel made of cast iron, titanium alloy, E-glass and aluminium alloy was reported. Findings: Based on the analysis, Aluminium alloy was found to be the most suitable material for constructing the flywheel. Specific tensile strength was considered for selection of the alternate materials of the flywheel. This paper also demonstrated the feasibility of using non-conventional materials like composite for manufacturing flywheels. Applications/Improvements: Flywheels which are a commonly used part in automobiles are subjected to multiple varying stress cycles which ultimately can lead to its failure.
\end{abstract}

Keywords: Alternate Materials, Engine, Flywheel, Gasoline, Performance

\section{Introduction}

The purpose of the flywheel is to smooth out power output due to the four stroke cycle of the IC engine. Flywheels are most commonly used in automobiles and are subjected to multiple varying stress cycles which ultimately can lead to its failure. They are also used in riveting machines to store energy from the motor and use it further during riveting operation. Flywheel is a mechanical device which is used as a storage device for rotational energy due to its significantly high moment of inertia ${ }^{1}$. Flywheels are required where there is a fluctuation in input power and output load is constant or where there is a fluctuation in output load and the input power remains constant ${ }^{2}$. Three factors account for the performance of the flywheel, namely material strength, rotational speed and geometry. The kinetic energy level produced by the flywheel and its specific energy is determined by its material strength ${ }^{3}$. The major advantage is the ability of the flywheel to handle high power levels. In automobiles large peak power is necessary during acceleration and with the use of electrical breaks; a large amount of energy is generated for a short while during braking which results in lower fuel consumption.

They demonstrated that by using optimization techniques various parameters like material and cost can be optimized and by applying an approach for modification of various working parameters like efficiency, output and energy storing capacity, the results were compared to the existing flywheel of material Grey Cast Iron ASTM $30^{7}$.

${ }^{*}$ Author for correspondence 
Akshay et al. analyzed a flywheel with Finite Element Analysis. A structural analysis was performed and normal stress and radial deformation was calculated. Flywheel was discredited into 19735 elements and 36539 nodes. S-Glass Epoxy can be used in flywheels to store energy with less mass. It can also be used in high speed applications 9 . S.M. Arnold made a deformation analysis of composite flywheel disc systems. The two major aspects of failure analysis, that is static and cyclic limit (burst speeds) were addressed. In case of static limit loads, a lower bound for disks with constant thickness was presented for the case of pure rotation as in case of a free spinning disk.

\section{Materials and Methods}

The flywheel was modeled using Solidworks 2013. The structural analysis of the flywheel made of cast iron was carried out using ANSYS Workbench 15.0. The materials used for the analysis were Al 6063-T6, Titanium alloy and E-glass and the structural analysis was carried out. The results were compared to obtain the best material suitable for the flywheel. The methodology has been shown in Figure 1A.

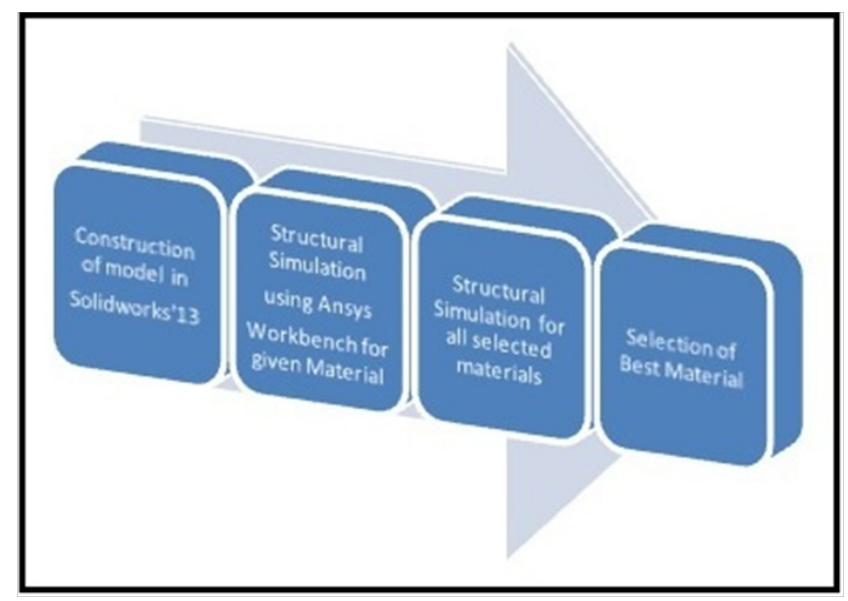

Figure 1. Methodology.

The selection of the materials was based on the ratio of tensile strength to the material density, also known as the specific tensile strength. The flywheel material with the highest specific tensile strength will yield the highest energy storage per unit mass ${ }^{11}$. The materials were selected using the graph as shown in Figure 1.

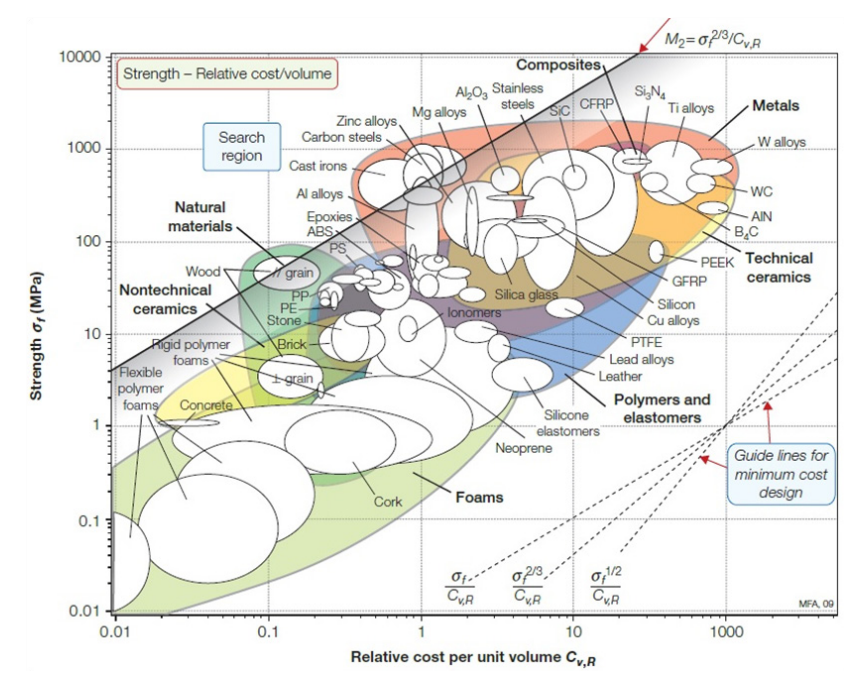

Figure 2. Graph of strength vs. density.

\subsection{Specifications of Selected Engine}

The flywheel of Subaru EJ25D gasoline engine from Forester 98 was selected for the analysis. The displacement, maximum power, maximum torque, number of cylinders, bore, stroke and compression ratio for the engine has been listed in Table 1.

Table 1. Engine specifications

\begin{tabular}{|c|c|}
\hline Model & Forester 98 \\
\hline Displacement & $2457 \mathrm{cc}$ \\
\hline Maximum power & $115 \mathrm{hp} @ 5600 \mathrm{rpm}$ \\
\hline Maximum torque & $190 \mathrm{Nm} @ 2800 \mathrm{rpm}$ \\
\hline Number of cylinders & 4 \\
\hline Bore & $99.5 \mathrm{~mm}$ \\
\hline Stroke & $79 \mathrm{~mm}$ \\
\hline Compression ratio & $9.7: 1$ \\
\hline Volume per cylinder & $614.25 \mathrm{cc}$ \\
\hline
\end{tabular}

\subsection{Modelling of the Flywheel}

$2 \mathrm{D}$ or $3 \mathrm{D}$ modeling can be carried out for constructing the flywheel. However, 3-D modeling was used to construct the flywheel as it gives more accurate results as compared to 2D modeling 9 . Figure 2 shows the dimensions of the Subaru flywheel. Figure 3 shows the exploded view of the 3D assembly with the flywheel, flexplate and spacer arranged from left to right.

\subsection{Analysis of the Flywheel using FEA}

ANSYS Workbench 15.0 was used for the analysis. The following assumptions were made for conducting the analysis: 


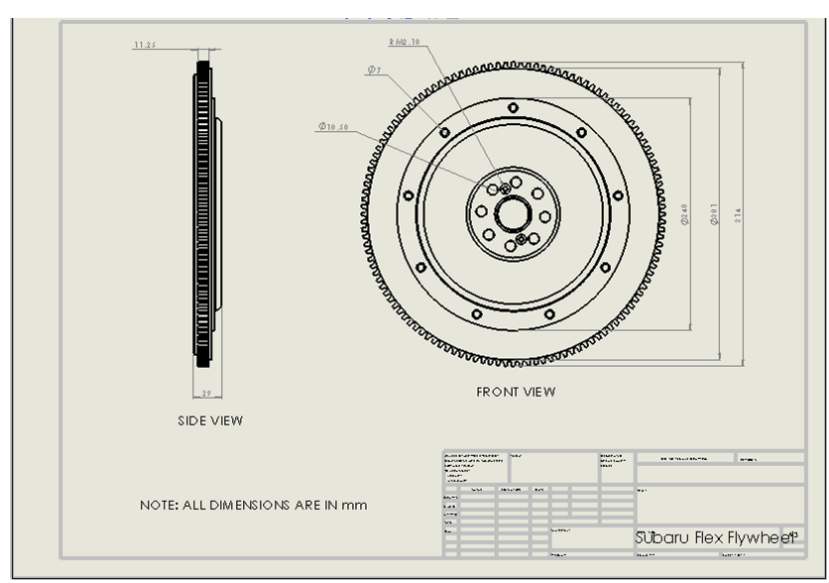

Figure 3. Dimensions of the flywheel.

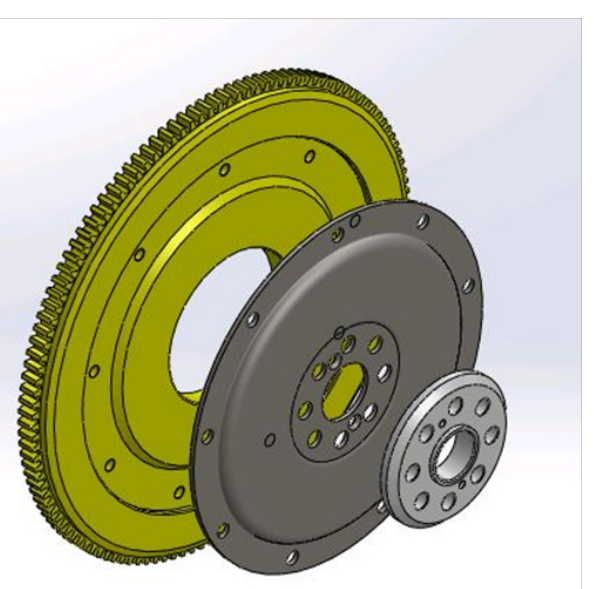

Figure 4. 3-D CAD model of Subaru EJ25D flywheel.

Assumption 1: The flywheel is considered is to be rotating at $4000 \mathrm{rpm}$ throughout the analysis for the various materials.

Assumption 2: The impact on the flywheel due to the engagement with the drive train is considered to be negligible during the analysis.

Assumption 3: It is assumed that only centrifugal forces act on the flywheel during engine operations.

Out of the four materials, titanium alloy is found to have the maximum value of young's modulus while minimum is that of E-glass. On the contrary, E-glass has the maximum while $\mathrm{Al}$ alloy has the minimum yield strength. Cast iron has the maximum density while E-glass has the minimum. E-glass has the maximum value of ultimate tensile strength and minimum value of poisson's ratio. $\mathrm{Al}$ alloy has the minimum tensile strength while maximum poisson's ratio is that of Ti alloy and $\mathrm{Al}$ alloy with a value of 0.33 .

The values of young's modulus, ultimate tensile strength, yield strength, density and poisson's ratio of the materials have been listed in Table 2 .

Table 2. Materials Properties

\begin{tabular}{|l|c|c|c|c|}
\hline $\begin{array}{l}\text { Parameter/ } \\
\text { Material }\end{array}$ & Cast iron & Al 6063 T6 & $\begin{array}{c}\text { Titanium } \\
\text { alloy }\end{array}$ & E-Glass \\
\hline $\begin{array}{l}\text { Young's } \\
\text { Modulus } \\
\text { (GPa) }\end{array}$ & 110 & 69 & 120 & 8.50 \\
\hline $\begin{array}{l}\text { Ultimate } \\
\text { tensile } \\
\begin{array}{l}\text { Strength } \\
\text { (MPa) }\end{array}\end{array}$ & 448.08 & 240 & 1220 & 2050 \\
\hline $\begin{array}{l}\text { Yield } \\
\text { Strength } \\
\text { (MPa) }\end{array}$ & 241.2 & 215 & 1034.2 & 2050 \\
\hline $\begin{array}{l}\text { Density (g/ } \\
\text { cm^3) }\end{array}$ & 7.3 & 2.7 & 4.8 & 2.6 \\
\hline $\begin{array}{l}\text { Poisson's } \\
\text { Ratio }\end{array}$ & 0.26 & 0.33 & 0.33 & 0.23 \\
\hline
\end{tabular}

\subsection{Meshing Method}

For the meshing the initial size seed being the active assembly and the smoothing is kept medium with fast transition and coarse span angle center. The element size of the mesh is $3.083 \mathrm{e}-005 \mathrm{~m}$. The mesh element type is of automatically generated triangular shape. The mesh elements are widely, flexibly and perfectly spread throughout the flywheel, making the analysis efficient and accurate.

\subsection{Boundary Conditions and Load}

A Cylindrical support is given at the shaft and flywheel contact, that is, the shaft-hole of the flywheel. The flywheel is radially and axially made fixed while it is free to rotate tangentially. The flywheel is rotated by 418.67 radians/s with the axis of rotation being the perpendicular line passing through the centre of the flywheel, outwards of the plane of flywheel. The rotational velocity of 418.67 radians/s is applied in steps of every 1 second linearly.

\section{Results and Discussion}

The flywheel has been divided into 48,055 nodes and 25,733 elements with ANSYS software for the sake of the analysis. 


\subsection{Radial Deformation Analysis}

The following trend was observed for the radial deformation:

$\mathrm{Al}<$ Cast iron $<\mathrm{Ti}<$ E-glass

The maximum deformation due to centrifugal force occurs in E-glass and the minimum in $\mathrm{Al}$ alloy, the reason for which can be contributed to their respective strength to the density ratio which was found to be the highest in case of $\mathrm{Al}$ and lowest for E-glass. The yield strength of $\mathrm{Al}$ is relatively less among the four, so the elastic modulus determines such behavior of aluminium alloys. The radial deformation is found to be maximum near the periphery and minimum near the center of the flywheel. This is because the centrifugal forces increase as we move towards the outer periphery of the flywheel from the center. Figure 4, Figure 5, Figure 6 and Figure 7 show the radial deformation for the different materials employed in structural simulation of the flywheel.

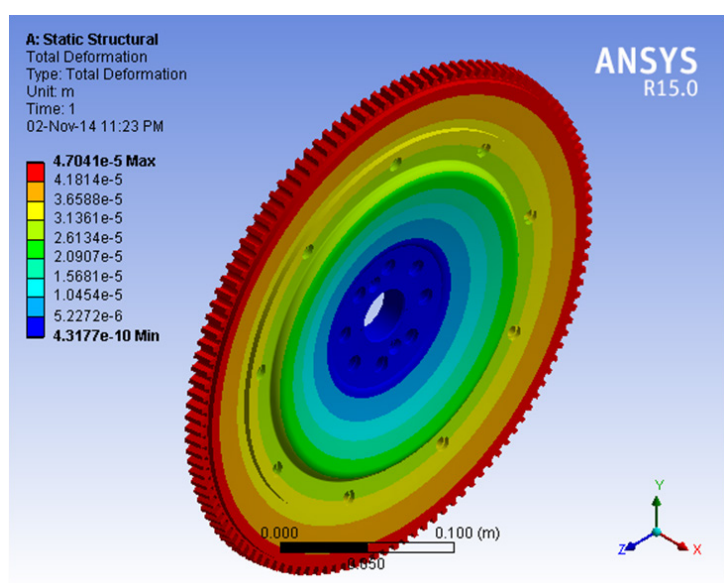

Figure 5. Radial deformation of cast alloy steel flywheel.

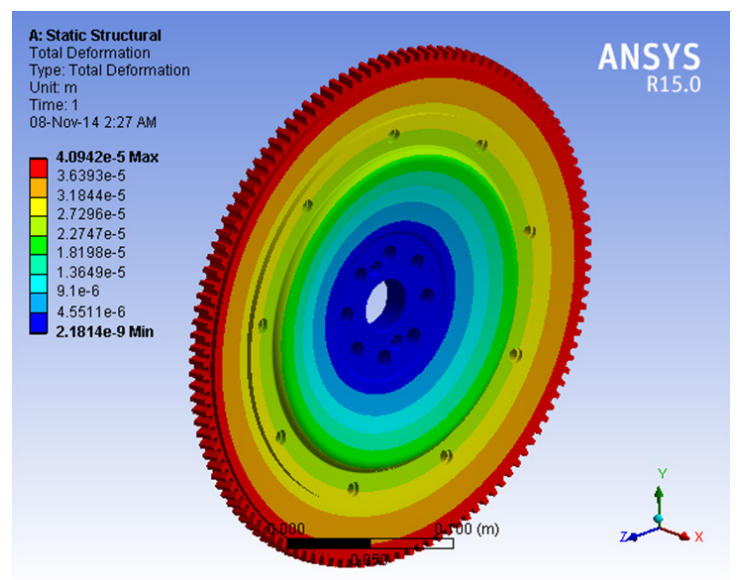

Figure 6. Radial deformation of Al $6063 \mathrm{~T} 6$ flywheel.

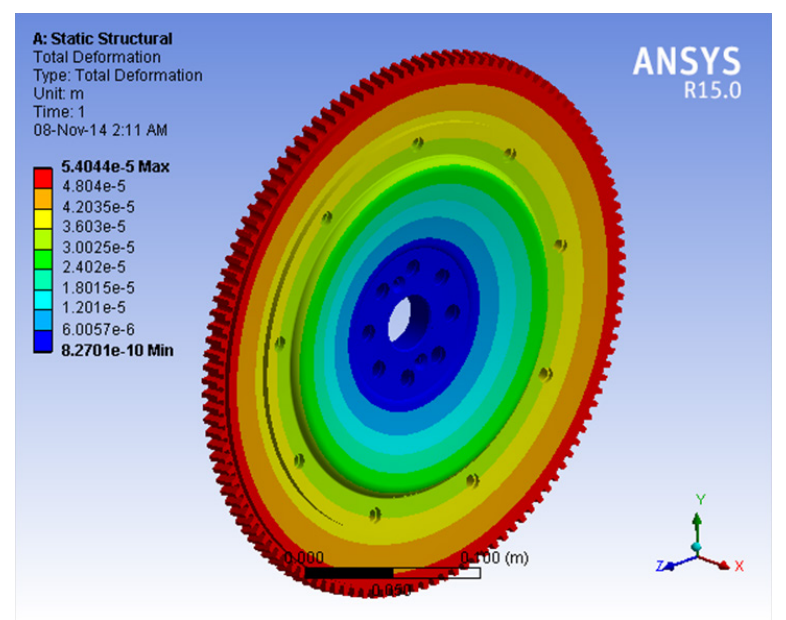

Figure 7. Radial deformation of Ti alloy flywheel.

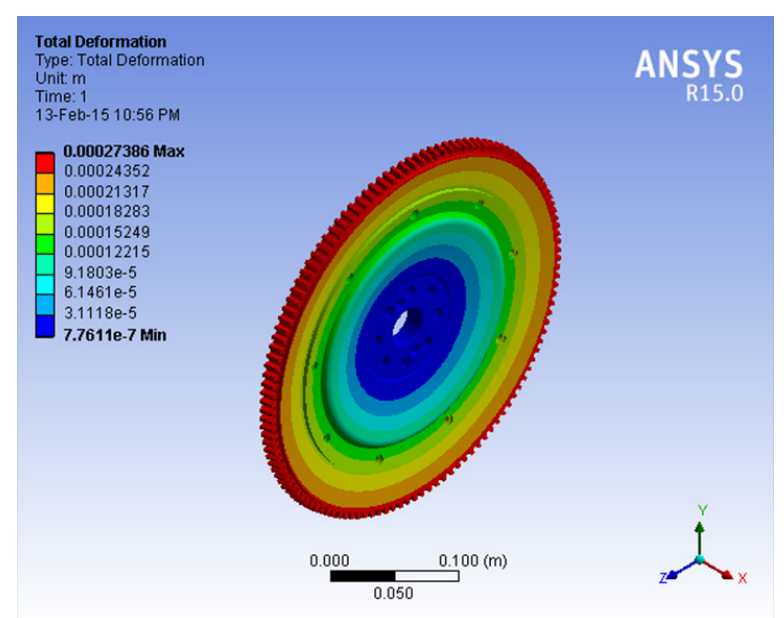

Figure 8. Radial deformation of E-glass flywheel.

\subsection{Radial Stresses Analysis}

The following trend was observed for radial stress analysis:

$\mathrm{Al}<\mathrm{Ti}<$ Cast iron $<$ E-glass

The maximum stress occurs in E-glass flywheel while the minimum occurs in $\mathrm{Al}$ alloy flywheel. One of the reason for this behavior can be attributed to the low strength to the density ratio for E-Glass and in the case of the aluminium, it can be proposed that as the strength to the density ratio is sufficiently high and the properties of aluminium alloy like light weight, high strength and high value of elastic modulus contribute towards minimum radial stress. In general, stiffer and lighter design can be achieved using aluminium alloys. Figure 8, Figure 9, Figure 10, and Figure 11 depict the radial stress for the different materials employed in structural simulation of the flywheel. 


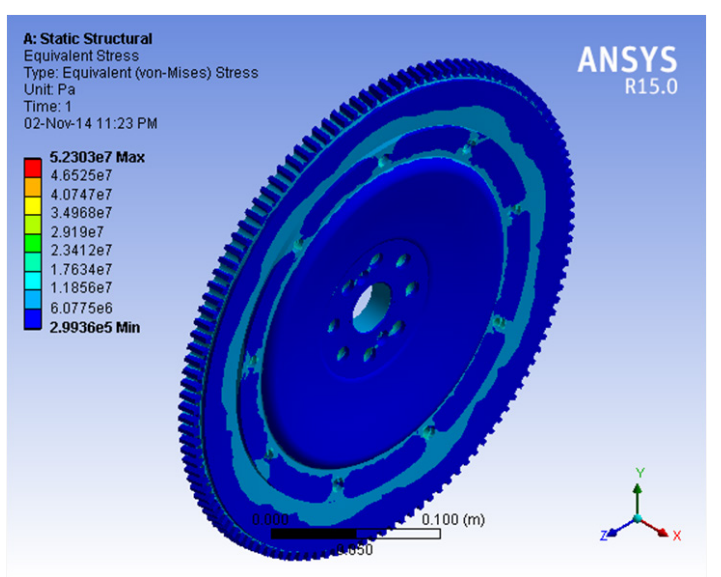

Figure 9. Radial stress developed in cast alloy flywheel.

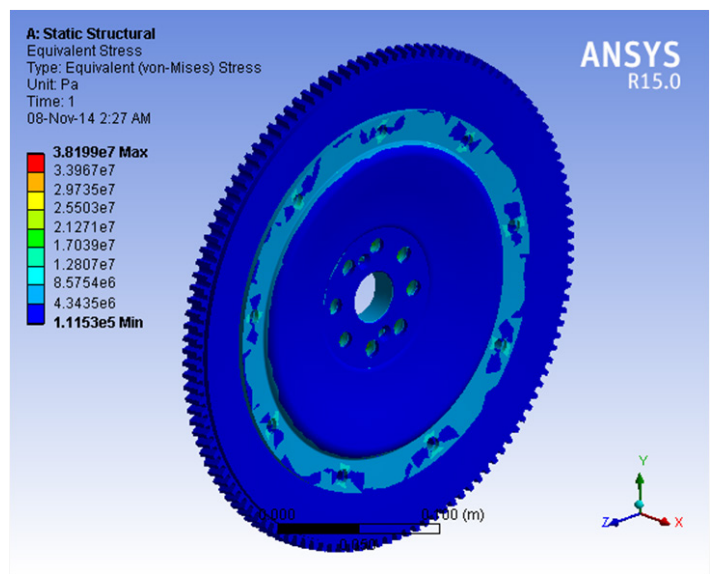

Figure 10. Radial stress developed in Al 6063 T6 flywheel.

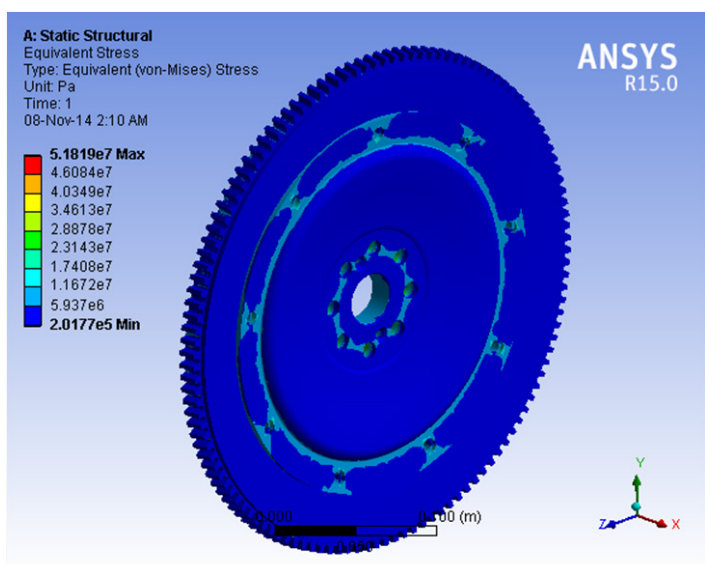

Figure 11. Radial stress developed in Ti alloy flywheel.

\subsection{Factor of Safety Analysis}

The factor of safety for the different materials of the flywheel are found to be within safe limits, which depicts that the flywheel designs are feasible and their manufacturing can be carried out for real time simulation. Figure 12, Figure 13, Figure 14, and Figure 15 shows the factor of safety for the different flywheels.

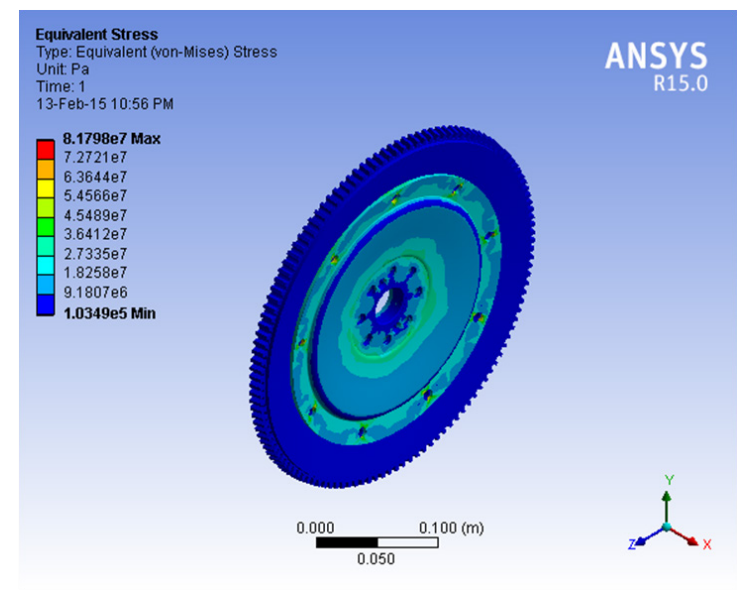

Figure 12. Radial stress developed in E-glass flywheel.

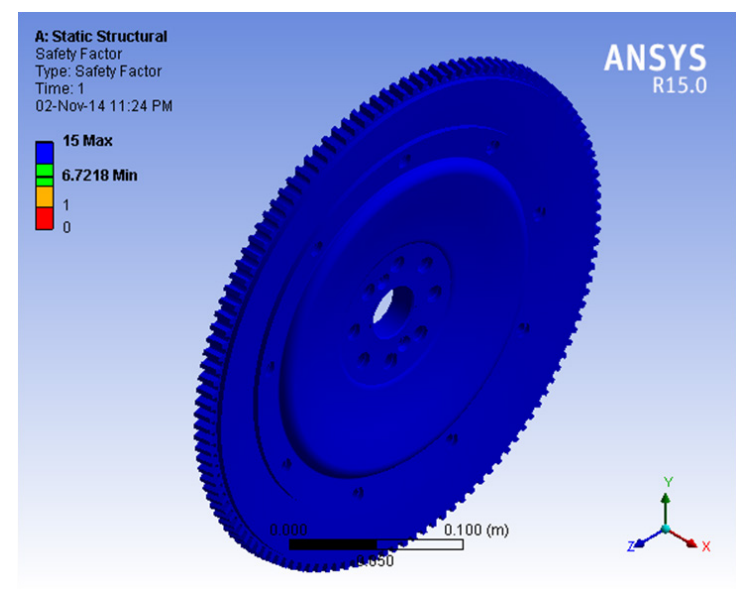

Figure 13. Factor of safety of cast alloy flywheel.

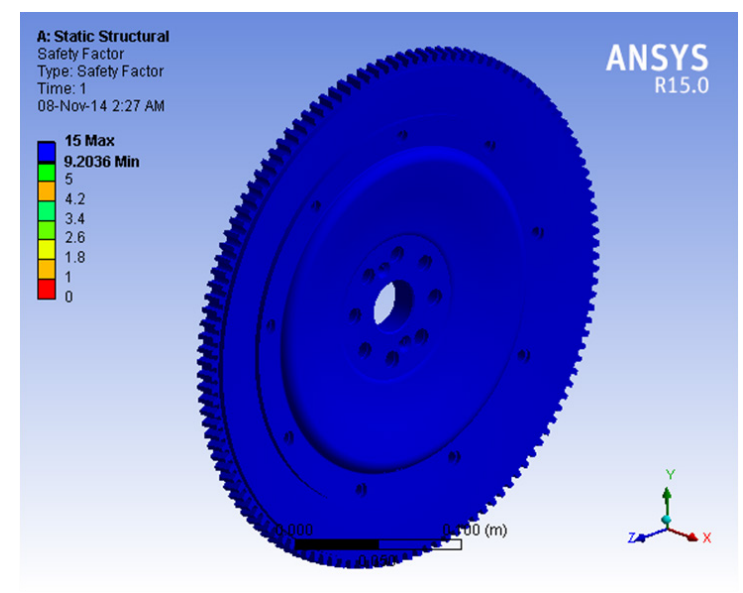

Figure 14. Factor of safety of Al 6063 T6 flywheel. 


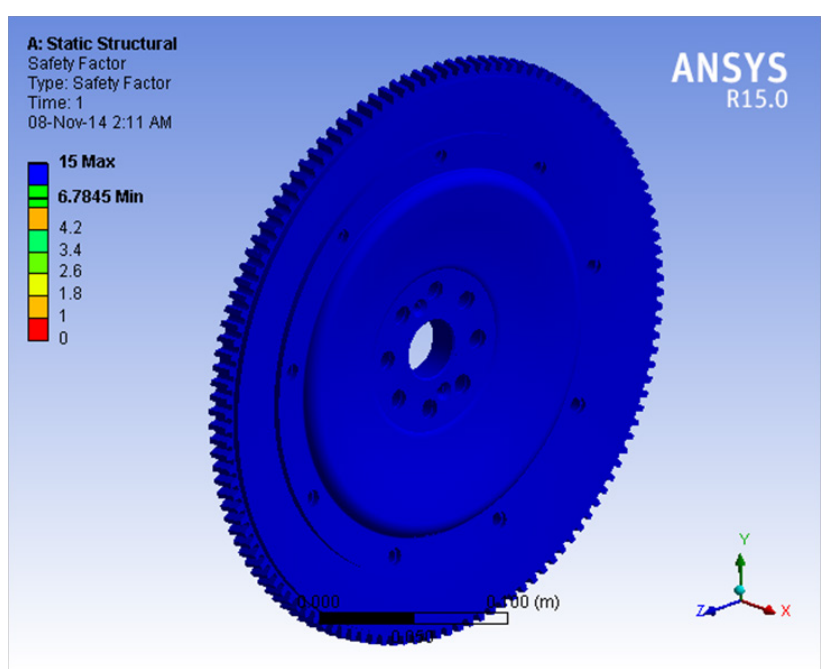

Figure 15. Factor of safety of Ti alloy flywheel.

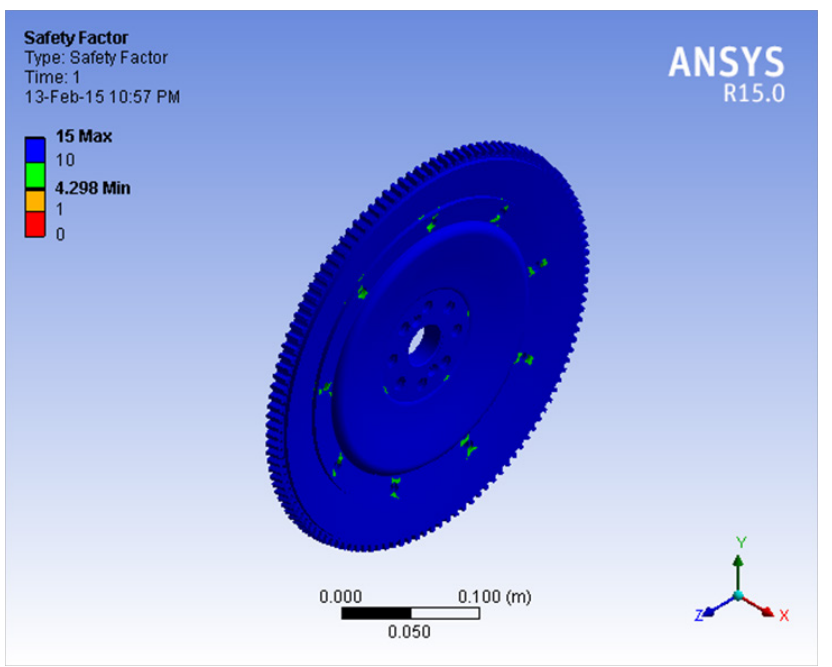

Figure 16. Factor of safety of E-glass flywheel.

The cast iron flywheel has the maximum weight while E-glass flywheel has the minimum weight. The results of the Finite Element Analysis (FEA) are listed in Table 3.

\section{Manual Calculations}

\section{Formula Used}

$$
\sigma_{t 1}=\frac{3}{4} * \rho * V^{2}
$$

$\sigma_{t 1}=$ Tensile force due to centrifugal force acting on rim.

$\rho=$ Density of material of rim

$\mathrm{V}=$ Linear velocity of rotation $=\frac{\Pi * \mathrm{D} * \mathrm{~N}}{\text { Calculation of Linear Velocity }(\mathrm{V})}$

Diameter of flywheel rim $=\mathrm{D}=0.314 \mathrm{~m}$

Speed of flywheel $=\mathrm{N}=4000 \mathrm{rpm}$

$$
\mathrm{V}=\frac{\Pi * \mathrm{D} * \mathrm{~N}}{60}=\frac{\Pi * 0.314 * 4000}{60}=65.76 \mathrm{~m} / \mathrm{sec}
$$

\section{Calculation of tensile force $\left(\sigma_{t 1}\right)$}

For Al-6063-T6

$$
\begin{aligned}
\sigma_{t 1} & =\frac{3}{4} * \rho * V^{2} \\
\sigma_{t 1} & =\frac{3}{4} * 2700 * 65.76^{2} \\
\sigma_{t 1} & =87,56,864.64 \mathrm{~Pa}
\end{aligned}
$$

Similarly, the values for the cast iron, Ti alloy and E-glass are obtained and are shown in the table 4.

Table 4. Material Properties

\begin{tabular}{|l|c|c|c|c|}
\hline Material & Al-6063C & Cast iron & Ti Alloy & E-Glass \\
\hline $\begin{array}{l}\text { Density } \\
(\rho),(\mathrm{kg} /)\end{array}$ & 2700 & 8900 & 4820 & 2600 \\
\hline Tensile & 87,56, & 288,65, & 156,32, & 84,32, \\
Strength ,(Pa) & 864.64 & 220.4 & 625.02 & 535.32 \\
\hline
\end{tabular}

\begin{tabular}{|c|c|c|c|c|}
\hline Parameter/Material & Cast iron & $\mathrm{Al} 6063 \mathrm{~T} 6$ & Titanium Alloy & E-Glass \\
\hline Mass of Flywheel (Kg) & 9.65 & 4.602 & 6.93 & 4.4924 \\
\hline Minimum radial Stress $(\mathrm{MPa})$ & 0.29 & 0.11 & 0.201 & 0.103 \\
\hline Maximum radial Stress $(\mathrm{MPa})$ & 52.3 & 38.1 & 51.81 & 81.97 \\
\hline Minimum Total Deformation (m) & $4.3 \times 10^{\wedge}-10$ & $2.181 \times 10^{\wedge}-9$ & $8.27 \times 10^{\wedge}-10$ & $7.76 \times 10^{\wedge}-7$ \\
\hline Maximum Total Deformation (m) & $4.7 \times 10^{\wedge}-5$ & $4.09 \times 10^{\wedge}-5$ & $5.4 \times 10^{\wedge}-5$ & $2.74 \times 10^{\wedge}-4$ \\
\hline Minimum Factor of Safety & 6.7218 & 9.2036 & 6.7845 & 4.298 \\
\hline
\end{tabular}

\section{Conclusion}

The modeling of the flywheel was performed using Solidworks 2013. The Finite Element Analysis (FEA) was carried

Table 3. Physical properties, radial stresses and deformation 
out using ANSYS workbench 15.0 for the four materials: cast iron, Al 6063-T6, Titanium alloy and E-glass.

The structural analysis of the original flywheel made of cast iron was carried out and the deformation, radial stress and the Factor of Safety (FOS) was reported. The material of the flywheel was changed to Al 6063-T6, Titanium alloy and E-glass in succession, and the structural analysis on ANSYS workbench was reported for each of the materials. The results of the deformation and stress analysis were found to be within safe limits. The manual calculations are also found to agree with the results obtained from the analysis. However, the deformation and stress developed for aluminium 6063-T6 flywheel was found to be the least among the four materials under consideration. $\mathrm{Al}$ alloy also has an added advantage of higher strength-to-weight ratio compared to the other materials. Thus, $\mathrm{Al}$ was found to be the best suited material for constructing the flywheel. Thus by using $\mathrm{Al}$ alloy flywheel, $52.31 \%$ of the weight can be reduced as compared to cast iron flywheel which can help in reducing the weight of the vehicle and increase the fuel economy. However, the life of the flywheel will also get affected.

This paper also highlights the importance of composites as an alternative for constructing the flywheel due to its high specific tensile strength. This is one reason why E-glass is a material of interest. Using E-glass will result in a weight saving of $53.44 \%$ as compared to the cast iron flywheel. However, the radial stresses and deformation are considerably more than that of cast iron which makes it unsafe for use with the engine. Further study can be done to identify composites which can be feasible for manufacturing flywheels with the help of structural analysis.

\section{References}

1. Phanindra M. Analysis of flywheel used in petrol engine car. International Journal of Engineering Research and Technology. 2014; 3(5).

2. Akpobi JA, Lawani IA. Computer-aided-design of flywheels. Advances in Engineering Software. 2006; 37(4):222-35.

3. Farde KD, Deshmukh DS. Review: Composite flywheel for high speed application. International Journal of Innovative Research in Advanced Engineering. 2014; 353-57.

4. Balasaheb SR, Rajmane M. A case study on design of a flywheel for punching press operation. International Journal of Engineering and Advanced Technology. 2014; 3(4):32-5.

5. Raut SR, Doshi NP, Gulhane UD. FEM analysis of flywheel used for punching press operation. IORD Journal of Science and Technology. 2014; 1(5):40-9.

6. Murugesan VM. An overview of automobile starting system faults and fault diagnosis methods. ARPN Journal of Engineering and Applied Sciences. 2012; 7(7):812-19.

7. Bawane SG, Ninawe AP, Choudhary SK. Analysis and optimization of flywheel. International Journal of Mechanical Engineering and Robotics Research. 2012; 1(2):272-76.

8. Bedier B, El-Naggar, Kholeif IA. Disk-Rim flywheel of minimum weight. Journal of American Science. 2011; 7(6):146-49.

9. Punde AP et al. Analysis of flywheel. International Journal of Modern Engineering Research. 2013.

10. Arnold SM, Saleeb AF, Al-Zoubi NR. Deformation and life analysis of composite flywheel disk systems, Elsevier. Composites Part B: Engineering. 2002; 33(6):433-59.

11. Dasseh M, Samer Y, Webb JF. A study on maximizing the energy density of a system by choosing a suitable flywheel. Global Journal of Technology and Optimization. 2015; 6(1):1-6. 